\title{
The Quality Issue of the Parts Blanked from Thin Silicon Sheets
}

\author{
Jacek Mucha and Jan Jaworski
}

\author{
(Submitted April 5, 2016; in revised form February 16, 2017; published online March 8, 2017)
}

\begin{abstract}
In this paper, the wear mechanism of punches made of M3:2 and M2 steel sheet which are used in blanking process of the rotor part of the low-power asynchronous motor was presented. The influence of additional TiN coating on the punch flank surface degradation intensity was described. The punch wear influence on the hardness changes close the material intersection surface was determined. The research results indicate that the tool durability ensures the quality of parts blanked from electrotechnical steel. The results will allow for selection of new tools materials for this type of tools which are used in difficult tribological conditions.
\end{abstract}

Keywords blanking process, electrical steel sheets, TiN coating, tool wear, wear

\section{Introduction}

The silicon steel sheet is commonly used for the manufacturing of the electrical machines stator and rotor parts. Most often they are produced s a single blanked parts which are assembled in the package. The most widespread and highly efficient manufacturing technology of this part is blanking process. The tool wear in blanking process results in increase in the concentration size of the plastic deformation in sheared blank close to the intersection surface (Ref 1). In the deformed silicon steel sheet, the undesirable residual magnetic appears, which causes increase the sheet structure grains pre-magnetization current during a passage of current direction change (Ref 2). In the case of electrical machines is not advantageous to increase in magnetic lossiness (Ref 1). The magnetic lossiness can be reduced by using the laser cutting process. The laser cutting processes have still smaller efficiency in comparison with the classic blanking process (Ref 3$)$. Furthermore, the laser cutting process generates material deformation (thermal) close to the cutting area, which causes a decrease in magnetic properties of electrical machines (Ref 4).

The blanking process of the parts with appropriate quality requires selection of the optimal process parameters (Ref 5, 6). Gréban et al. in their paper (Ref 5) presented the effects of parts blanking from copper alloy sheets material. Tekiner et al. (Ref 6) presented the experimental analysis results of the blanking process for aluminum alloy parts. The effects of the aluminum alloy structure changes in the blanking and bending process

Jacek Mucha, Department of Mechanical Engineering, The Faculty of Mechanical Engineering and Aeronautics, Rzeszow University of Technology, al. Powstańców Warszawy 8, 35-959 Rzeszow, Poland; and Jan Jaworski, Department of Manufacturing Processes and Production Engineering, The Faculty of Mechanical Engineering and Aeronautics, Rzeszow University of Technology, al. Powstańców Warszawy 8, 35-959 Rzeszow, Poland. Contact e-mails: j_mucha@prz.edu.pl and jjktmiop@prz.edu.pl.

were presented by Ravela et al. (Ref 7). They showed that the grains size of blanked sheet affects on the intersection surface quality and burr height.

The wear, during the blanking process, causes the change of cutting surface quality and the burr height (Ref 8-16). As a result of tool cutting edge friction wear the cutting radius increase, which significantly affects on the blanking process energy consumption (Ref 12,13), whereas Hernández et al. (Ref 8) studied the effect of punch flank surface wear on the burr height. In studies, the change of punch cutting edge was modeled, and the burr height on stainless steel blanked part edge was observed. He demonstrated that there is an optimal value of punch-die clearance due to the burr height. The burr height can be reduced by using appropriate blanking clearance (Ref 9-15).

Depending on material group and sheet thickness, the recommended values of blanking clearance are assumed (Ref 15). These are indicative values (Table 1). The pun-die clearance affects on the sheet material separation process; hence, the sheared blanks surface quality is obtained (Ref 17). The clearance value is particularly important in blanking process of very small and accurate parts (Ref 18).

Due to the sharp edges and the burr on the blanked elements before coiling winding the insulation is applied (Fig. 1). The paper insulation in the grooves protects windings from wire coating damaging. Additional insulation increases electrical motor production costs and manufacturing time. Hence, it is reasonable to carry out research related to burr height reduction and its changes as a results of cutting edge wear.

Number of factors, including the material type, influence on the tool flank surface wear during the blanking process (Ref 19). The most commonly used materials for blanking tools are the casted high-speed steels such as M2, K945, M42 and steels manufactured by sintering technology such as ASP23, ASP30, ASP60 (ASP-Asea Stora Process) (Ref 16). Tool material development is related to increasing of tool lifetime by improving mechanical, tribological and thermophysical properties of tool material. One of these ways is to increase the mechanical properties, including wear resistance, by modification surface of the blanking tools.

Anti-wear coatings (applied by PVD or CVD method) on the cutting tools reduce the intensity of flank surface and 
Table 1 Cutting clearance per side (percentage of stock thickness) (Ref 15)

\begin{tabular}{lll}
\hline Material & Irregulars contour, \% & Round, \% \\
\hline Aluminum & & 2 \\
Soft, less than $3 / 5^{\prime \prime}$ thick & 3 & 3 \\
Soft, more than $3 / 5^{\prime \prime}$ thick & 5 & $4-6$ \\
Hard & $5-8$ & 2 \\
Brass and copper & 3 \\
Soft & 4 & 3 \\
Medium & $5-6$ & 4 \\
Hard & & 2 \\
Steel & 3 \\
Low carbon soft & 4 \\
Medium & 5 \\
Hard & $4-5$ \\
Silicon steel & $5-8$ \\
Stainless steel & 2 \\
\hline
\end{tabular}

(a)

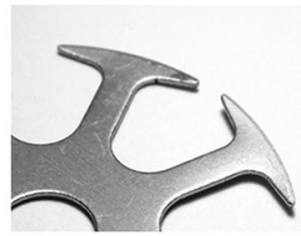

(c)

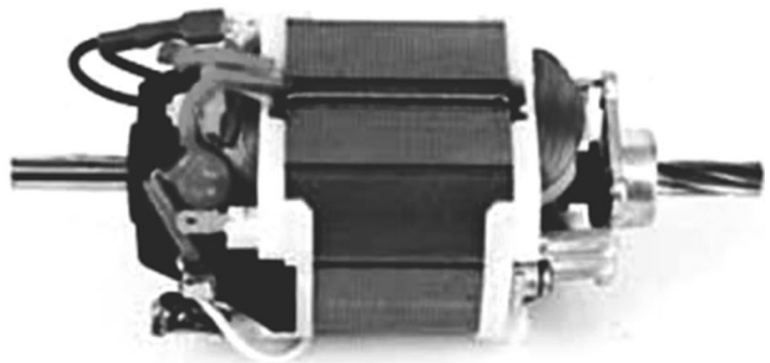

Fig. 1 Electric motor construction: (a) a single element of rotor, (b) rotor with windings and paper insulation in the grooves, (c) electrical motor assembly

cutting edge wear. The tribological aspects of TiN coating on the M2 steel were presented in the Hong et al. paper (Ref 20). Cheung et al. (Ref 21) studied the influence of blanking process parameters change, in this the ASP30 punch material, on the shearing edge wear rate in blanking process of stainless steel sheets and aluminum alloy sheets. He studied the additional TiN coating layer influence on the punch wear process. Punch material has an impact on the cutting edge wear process. A wide range of blanking test of C5191-RH $(0.254 \mathrm{~mm})$ phosphorous bronze sheet, for different punch materials, is presented by Lo et al. (Ref 22).

In the case of blanking process of materials with special mechanical properties, it is reasonable to carry out an experimental research to determine appropriate parameters of cutting process.

In present paper, the wear mechanism of the M2 and M3:2 steel punches used in the process of the part blanking from M530-50A silicon steel sheets was described. The analysis of the tool wear influence on the intersection surface quality of rotor sheets and on the hardening zone change was presented.
Results of experimental research of punch-die clearance influence on the intersection surface quality were discussed.

\section{Experimental Procedure}

\subsection{Blanking Process Methodology}

The research was conducted to explain the tool wear mechanism during part blanking process of the M530-50A silicon steel sheet. The blanking process was carried out in industrial conditions. The wear test was conducted during the blanking process of the rotor and stator sheet plates used in low-power asynchronous electrical machine-Fig. 2(a). Different values of the punch-die clearance and different tools materials were used. The blanking clearance of $\left(L_{z}\right)=0,4$ and $8 \%$ was defined as follows (Fig. 2b):

$L_{z}=\frac{s}{t} \times 100(\%)$,

where $t$-sheet thickness, $s$-one side clearance (Fig. 2b) determined from the relation

$s=\frac{D-d}{2}(\mathrm{~mm})$,

where $D$-die hole dimension, $d$-punch dimension in tool axial cross section.

The blanking process was carried out up to 800,000 cuts. Then the tools were sharpened. The blanking speed value was constant (200 cuts/min).

In experimental analysis of the tool wear effect on the intersection surface quality punches made by M2, M3:2 steel material and materials with TiN coatings (M2+TiN, M3:2+TiN) were used. The chemical compositions of these materials are presented in Table 2. The M3:2 steel (ASP 23 Vanadis, Powder Metallurgically Produced High Speed Steel) is a material with $7980 \mathrm{~kg} / \mathrm{m}^{3}$ average density and HRC 66 hardness after toughening, and M2 steel has $7750 \mathrm{~kg} / \mathrm{m}^{3}$ average density and 63 HRC hardness. The punch coatings were applied by physical vapor deposition (PVD) method. The TiN coating had a yellow color, about 2300 HV5 hardness and 3.5-4 $\mu \mathrm{m}$ of thickness.

In experimental research of punch wear influence on the intersection surface quality and on the material hardness change 
close to the cutting edge of rotor sheets, the M530-50A (M 45 according AISI standard) silicon steel sheet was used. The sheet thickness was $t=0.5 \pm 0.02 \mathrm{~mm}$. The chemical composition and mechanical properties are presented in Tables 3 and 4. The

(a)
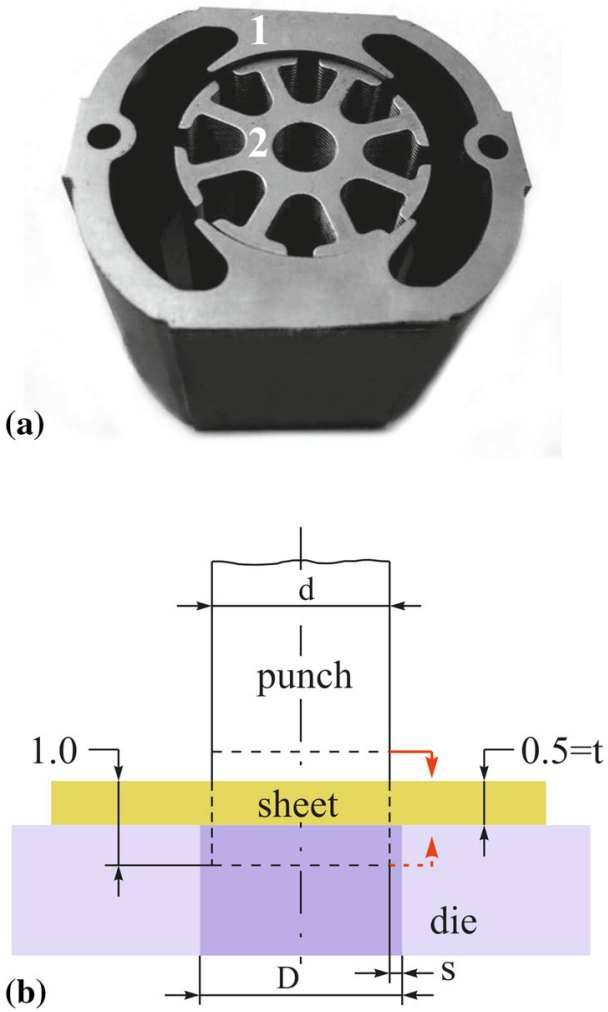

Fig. 2 Stator (1) and rotor (2) elements blanked from silicon steel sheet (a), and the tool arrangement during the blanking process (b) primary structure of sheet material is presented in Fig. 3. The sheets had a C6-type insulating coating of $\sim 7 \pm 1.5 \mu \mathrm{m}$ thickness (Ref 23). The C6 coating layer is applied by manufacturers of these silicon steel sheets types. The mineral elements have been selected to reduce punching tool wear and favor punching oil retention. They also enhance the rigidity of the varnish, which minimizes dimensional changes under high pressure/temperature.

\subsection{Measurements and Observations Methodology}

During the blanking tools wear increasing, the burr height on the blanked parts is changing (Ref 24). By measuring of the burrs height, the tool exploitation phase can be determined-indirect method (Fig. 4).

The bur height measurements were realized only for rotor sheets edges (Fig. 5a) on the test stand with Taylor Hobson SUTRONIC $3+$ surface analyzer. The measurement accuracy was $\pm 0.5 \mu \mathrm{m}$. The measurement idea is presented schematically in Fig. 5(b). The arrangement of the planes of the profilograph gauging point movements in accordance with the burrs line is presented in Fig. 5(c). Measurements on selected measuring length were done for four points, in which the maximal burr height was observed. For these points, the measurements were repeated three times. Examples of measurement results are presented in Fig. 6. The average burr height was calculated from the formula presented in Fig. 6(b). In addition, selected parts of the punches were scanned by using Taylor Hobson inductive scanning head. This allowed to make a topography of the blanking tools.

The observation and the measurement of the zones on the blanked part intersection surface (Fig. 7) were done by using Optech XJL-17 optical microscope with Satisec 81UP CCD digital camera.

The area of material changes was determined by indirect method-hardness measurement. The material hardness was measured by using MATSUZAWA microhardness equipment. Pyramid with $136^{\circ}$ apex angle was used as a penetrator. The

Table 2 Chemical composition of punches material (wt.\%)

\begin{tabular}{lllllllllll}
\hline & \multicolumn{10}{c}{ Chemical elements } \\
\cline { 2 - 10 } Material & C & Mnmax & Simax & Pmax & Smax & Cr & W & Mo & V & Fe \\
\hline M2 (SW7M) & $0.82-0.92$ & 0.4 & 0.5 & 0.03 & 0.03 & $3.5-4.5$ & $6.0-7.0$ & $4.5-5.5$ & $1.7-2.1$ & Rest \\
M3:2 (ASP 23) & $1.19-1.21$ & $\ldots$ & $\ldots$ & $\ldots$ & $\ldots$ & $4.11-4.13$ & $6.33-6.37$ & $4.6-4.8$ & $3.1-3.2$ & Rest \\
\hline
\end{tabular}

Table 3 Chemical composition of M530-50A silicon steel sheet material (wt.\%)

\begin{tabular}{lccccccccc}
\hline $\mathbf{P}$ & $\mathbf{C}$ & $\mathbf{S i}$ & $\mathbf{S}$ & $\mathbf{M n}$ & $\mathbf{C r}$ & $\mathbf{N i}$ & $\mathbf{C u}$ & $\mathbf{A l}$ & $\mathbf{F e}$ \\
\hline 0.01 & 0.01 & 1.43 & 0.007 & 0.365 & $<0.01$ & $<0.01$ & 0.05 & 0.335 & Rest \\
\hline
\end{tabular}

Table 4 Mechanical properties of M530-50A (material No. 1.0813) silicon steel sheets material

\begin{tabular}{|c|c|c|c|c|c|c|}
\hline $\begin{array}{l}\text { Yield } \\
\text { strength } R_{0.2} \\
\text { (MPa) }\end{array}$ & $\begin{array}{c}\text { Tensile } \\
\text { strength } R_{\mathrm{m}} \\
\text { (MPa) }\end{array}$ & $\begin{array}{c}\text { Reduction } \\
\text { of } \operatorname{area} Z(\%)\end{array}$ & $\begin{array}{c}\text { Fracture } \\
\text { elongationA5 (\%) }\end{array}$ & $\underset{\left(\mathrm{mm}^{2}\right)}{\operatorname{Area} S_{\mathrm{o}}}$ & HardnessHV5 & $\begin{array}{c}\text { Young's modulus } E \\
\text { (MPa) }\end{array}$ \\
\hline 245 & 417 & 33 & 61 & 10 & 126 & $2.2 \mathrm{e}+5$ \\
\hline
\end{tabular}


measurement was carried out at load of $0.100 \mathrm{~kg}$ with the penetration time set up to $10 \mathrm{~s}$. Initial hardness before sheet blanking process was 145 HV0.1 (average from 5 measurements). The distance between measuring point was determined on $0.05 \mathrm{~mm}$, and the measurement points grid is presented in Fig. 8.

The hardness measurements were always carried out from the base point (point on the measurement points grid in Fig. 8). Depending on the intersection edge, contour measurements were done in points in material. These points of measurement points grid beyond the material were excluded. Results were used in computer program so as to have the same base (two lines in Fig. 8). Then it was possible to create a graphs. The

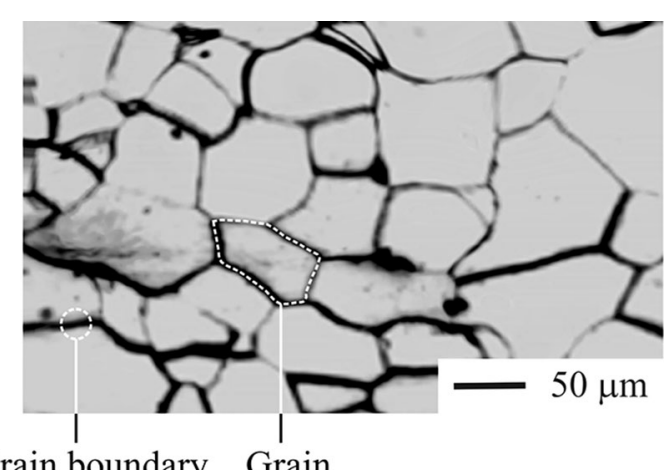

Grain boundary Grain

Fig. 3 Structure of M530-50A silicon steel sheet material

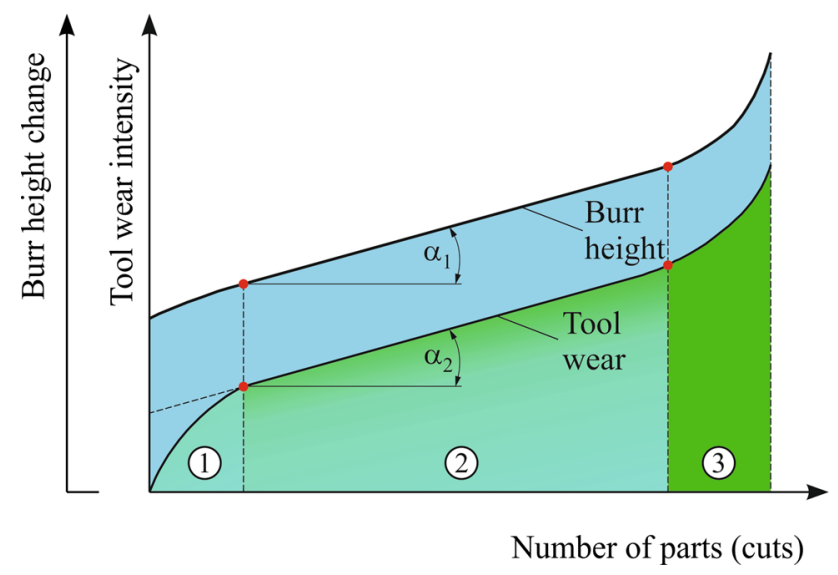

Fig. 4 Tool wear curve with the work periods and burr height curve of the blanked element (1-running-in period, 2-period of moderate wear, 3 - period of accelerated wear) hardened area positions on the sheet samples are presented in Fig. 9.

\section{Results and Discussion}

\subsection{Tool Wear}

During the blanking process, the punches are wearing-out especially on the punch flank surface on the distance of sheared blanks pushing out from the separation zone (Fig. 2b). A preliminary observation by an optical microscope was done after 500,000 sheared blanks for M2 and M3:2 punch materials and the punch-die clearance of $8 \%$ (Fig. 10). The abrasive wear was observed. On the tool flank surface, the very small hard and crushed particles "2" were clearly visible (Fig. 10a). Under the pressure of the blanked sheets, these particles are adhering. This is an adhesive wear of the tool surfaces. Hard particles adhered to the tool surfaces affect on the flank surface defecting during the blanking process. For the M3:2 material, the particles adhered boundary is clearly visible (Fig. 10b). The concentration of the adhered particles was observed on the contact line ends between blanked material and punch material. On the surface between cutting edge and end of material-punch line contact, the scratches were observed. Subsequent analysis was carried out after 3D surface scanning.

In general, the material degradation and loss of the material in the outer layer of abrasive wear are related to:

- microcutting, when $A_{\mathrm{b}} / A_{\mathrm{g}}=0$;

- ridging (plastic deformation in the contacts area and upsetting of the material form each side of groove) when $A_{\mathrm{b}} /$ $A_{\mathrm{g}}=1$;

- scratching (material is partially plastically deforming and partially cutting in the form of the micro-chips as a products of the wear process), when $0 \leq A_{\mathrm{b}} / A_{\mathrm{g}} \leq 1 . A_{\mathrm{b}, \mathrm{g}}$ was determined in relation to the punch base surface (Fig. 11).

The primary tool flank surface of M3:2 material is presented in Fig. 12a. After 500,000 sheared blanks, numerous adhered of abrasion product was obtained (Fig. 12b). The abrasion products were moved from cutting edge to inside of cutting surface. Areas of abrasion product accumulation were created. With increasing of cuts number to 800,000 the surface close to cutting edge had a bigger material losses-Fig. 12c. After 500,000 cuts (with the $4 \%$ clearance), the punch made of M2 material had a numerous signs of wear on the flank surface such as scratches and grooves (Fig. 13). Further test, with this value of punch-die clearance, was stopped due to the high value of burr on the part edges. The surface of M3:2 punch material,



(a)

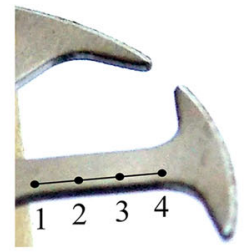

Fig. 5 Burr height measurement on the blanked rotor part: scheme

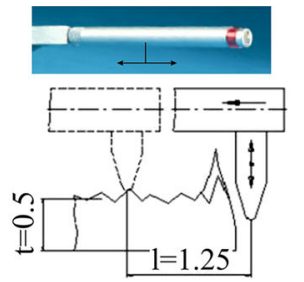

(b)

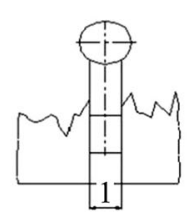

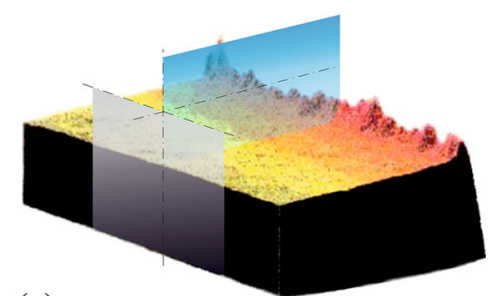

(c) (a) measuring line in rotor sheet plates,

(b) measuring idea, (c) planes arrangement 

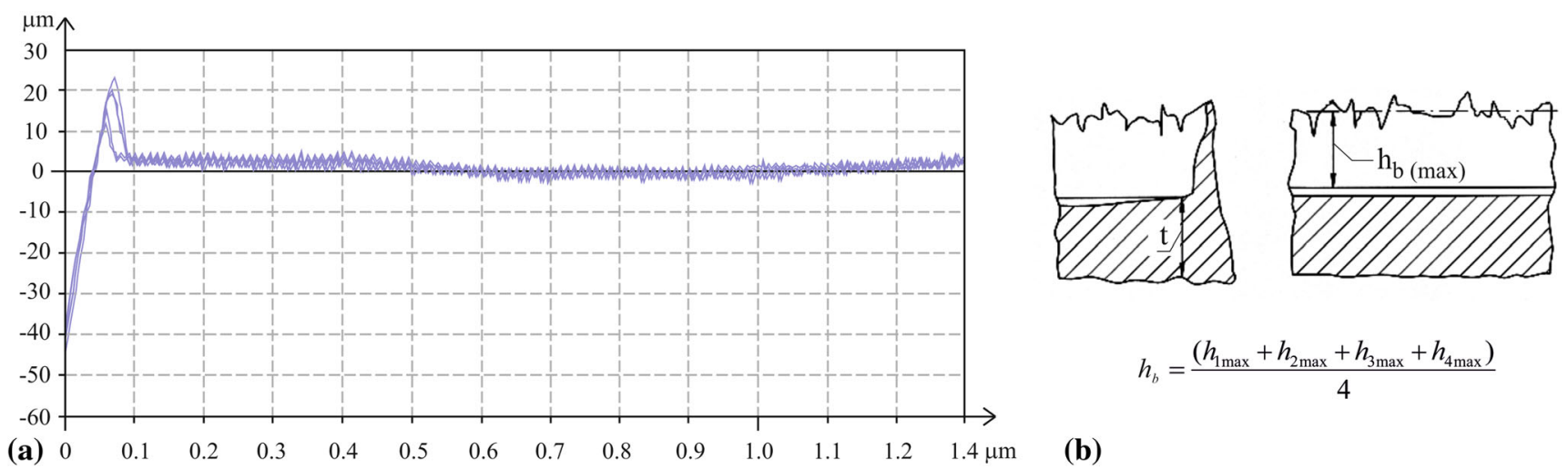

$$
h_{b}=\frac{\left(h_{1 \max }+h_{2 \max }+h_{3 \max }+h_{4 \max }\right)}{4}
$$

(b)

Fig. 6 Examples of burr height measurement (a), formula for calculation of average burr height (b)



(a)

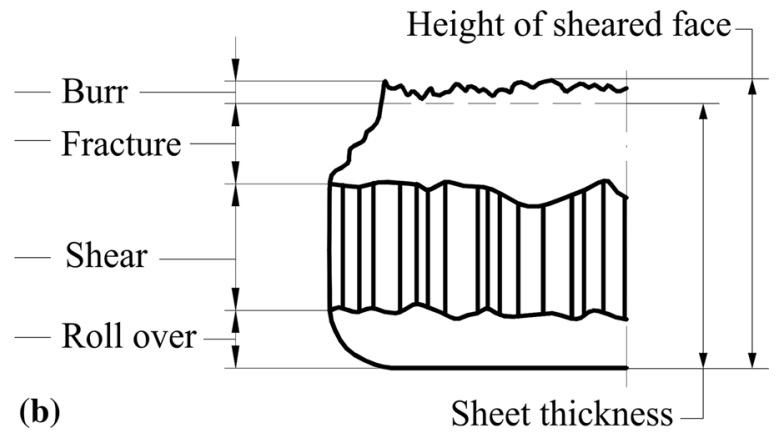

Fig. 7 Intersection surface: (a) characteristic zones, (b) total height of the intersection surface

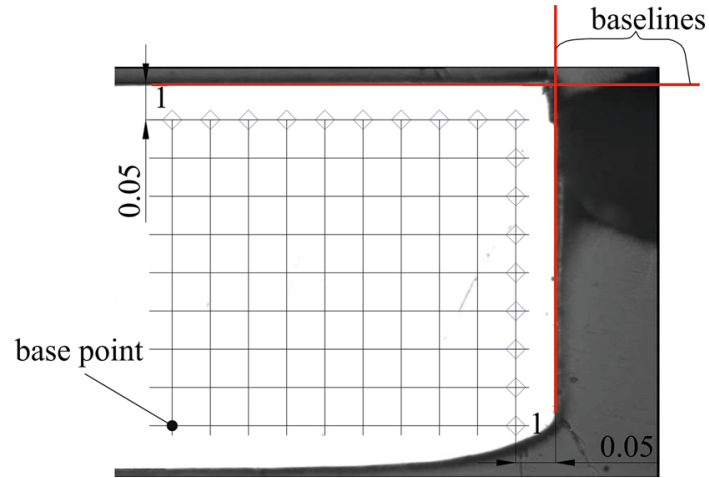

Fig. 8 Measurement points grid to determining the hardness changes close to the cutting edge

after 500,000 sheared blanks, was in better condition and characterized by a smaller degradation (Fig. 12b and 13).

Next analysis of the punch surface wear was presented for tools with TiN coating and 0 and $8 \%$ values of punch-die clearance. The contact between punch and unleashed silicon steel sheets caused an abrasive wear process (Fig. 14). The dark zone on the punch circumference shown that in the TiN coating layer the microstructures was changed. The intensity of the microstructure changes was observed after more number of cuts.

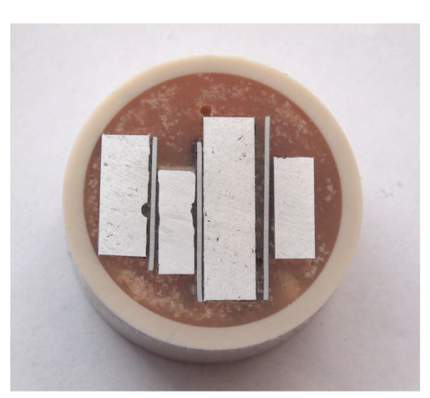

(a)

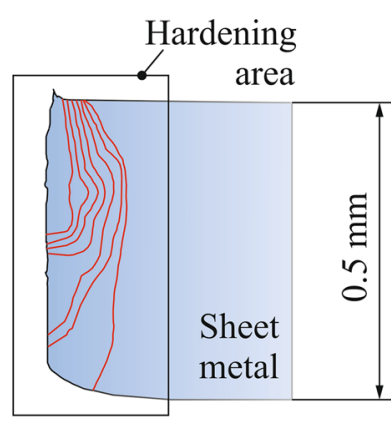

(b)
Fig. 9 Samples for metallographic observation (a), and the observation area close to the intersection surface on the part cross section (b)

The microstructure of the M3:2 sintered steel in comparison with M2 casted steel is more uniform and refinement (Ref 25). The M2 steel has a higher ductility, so therefore is more susceptible on ridging (Fig. 12b and 13). Reduction in this phenomena intensity can be obtained by using titanium nitride (TiN) coatings. For tools made of M3:2 steel due to the structure refinement, abrasive wear and microspallings were observed (Fig. 12b). After unleashing the silicon steel sheet, the contact of hard inclusions in silicon steel sheet with inclusion in 


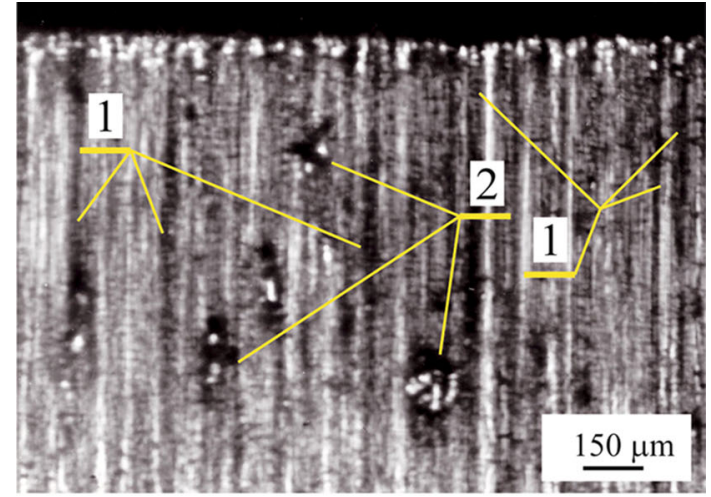

(a)

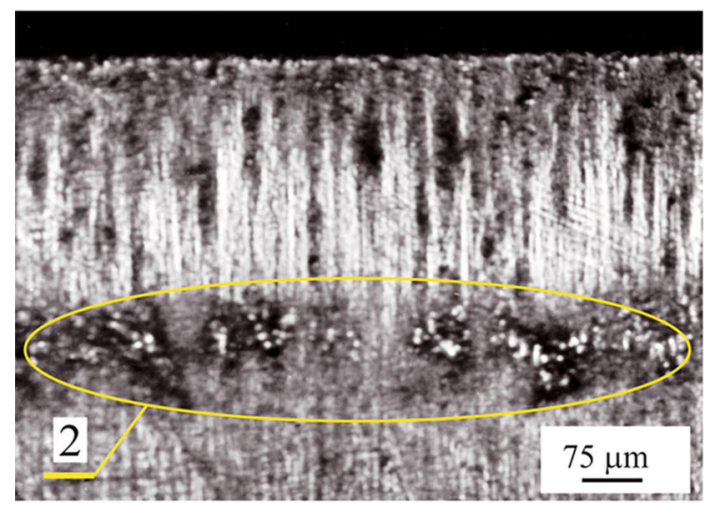

(b)

Fig. 10 Punch flank surface after 500,000 sheared blanks: (a) M2; $80 \times$ zoom, (b) M3:2; $160 \times$ zoom ( $8 \%$ of blanking clearance, surface image)

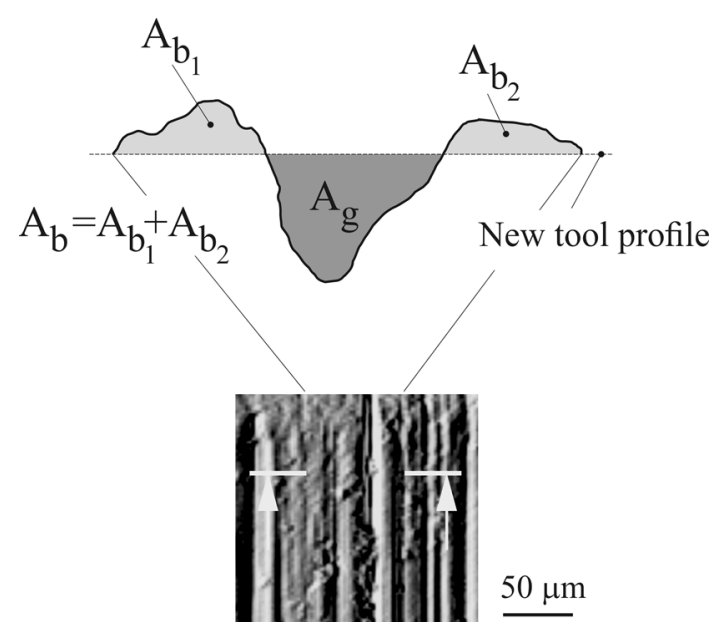

Fig. 11 Wear types criterion $\left(A_{\mathrm{g}}\right.$-material cross section which has been removed (groove), $A_{\mathrm{b}}$-material cross section close to this scratches)

punch material was obtained. As a result of cyclical repetition of this process, the gradual degradation of the tools surface was observed.

The tool wear and its intensity are related to the blanking process parameters. The wear heavily depends on the tools protective coatings and the technology of coating applying (Ref
26). The punch wear has an influence on the blanking process energy consumption (Ref 13).

For the 800,000 sheared blanks, the greatest wear was obtained for the $0 \%$ of punch-die clearance (Fig. 15). With increasing of cuts number, the abrasion product is adhered and moved with the punch movement. In the case of a strong adhesion of coating and adhered particles, the TiN layer degradation and punch material unleashing were obtained.

Punches made of M3:2+TiN materials were more resistant to wear than punches made by M2+TiN materials. In Fig. 16 and 17 , some examples of tool surface scanned by $3 \mathrm{D}$ scanning head and observed on the scanning microscope were presented. On the tool surface scan after several thousands of cuts, some TiN coating layer thickness decrement was obtained (Fig. 18). Close to the tool edge, the TiN coating layer was completely destroyed. In the case of blanking with the $8 \%$ of blanking clearance, small flank surface wear was observed. The coating layer was undamaged except a few long grooves (longitudinal cavities). Hard inclusions, which may contain a sheet material, scratch the punch flank surface. In some zones, small spalling of the coating layer occurred (Fig. 17b). From the tool front, the coating layer was wear-out less than in case with $0 \%$ of blanking clearance. In blanking process with $0 \%$ of blanking clearance, the tool face surface was wear-out less and tool flank surface was wear-out more (Fig. 15b).

During the blanking process with high value of the blanking clearance $(8 \%)$, the sheet is bending and the sheet material is moving alone the punch face surface. Hence, the tool face surface is wear-out more intensively (Fig. 15a). In addition, value of the punch edge radius is increasing. The surface degradation for punch made of M3:2+TiN materials (Fig. 17b) is different than in the case of punch made of M2+TiN materials (Fig. 16b). Similar differences in wear were observed in the case of punch-die clearance of $0 \%$ for punch with and without TiN coating layer (Fig. 17a). High-speed steel (casted steel) is less resistant to ridging. After a certain time, the coating layer in zones of strong ridging is spalling (Fig. 16 and 17). The M3:2 sintered steel is more wear resistant. In both cases, the TiN coating layer inhibits the flank surface wear. However, the friction process caused that the coating layer is damaging, the punch material is unleashing, and the layer boundary is changing with increasing of cuts numbers (Fig. 19b). The friction process causes that the coating was damaged and punch material was exposed. The boundary of punch material exposition is changed with increase in cuts number (Fig. 16b). The coating layer boundary is not linear. On the detail, the remaining layer was observed (see detail in Fig. 16b). The line layout is not a result of the TiN coating layer wear. These are the microcavities obtained during the punch manufacturing by using the wire electrical discharge machine.

\subsection{Burr and Intersection Surface}

The changes in the sheared blank magnetic properties are caused by intersection surface shape error, by burr on the edge and by increase in material hardness close to the intersection line (Ref 2-4, 27, 28). Therefore, the quality control of the intersection surface after blanking process is an extremely important, in the case of magnetic materials. The sizes of the intersection zones during the blanking process are changing (Ref 14).

Tool wear which increases with blanking time causes the size change of the sheared blanks zones (Fig. 19). For 0 and $8 \%$ of the blanking clearance and initial cuts, the differences of the intersection zones were observed (Fig. 20). The changes of 


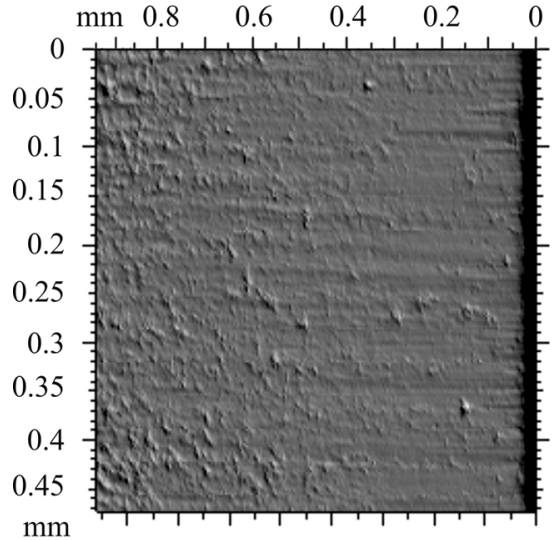

(a)

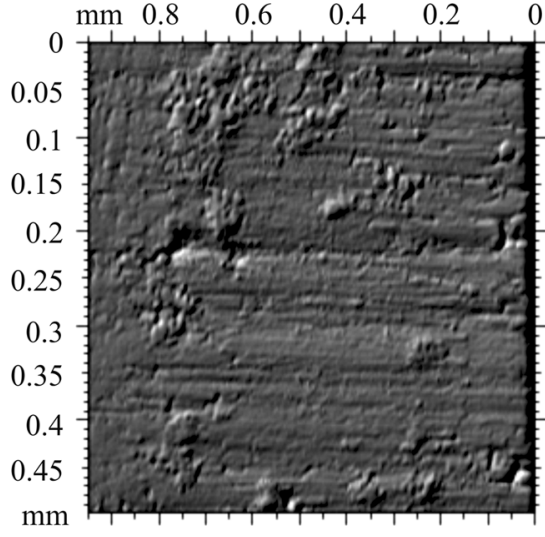

(b)

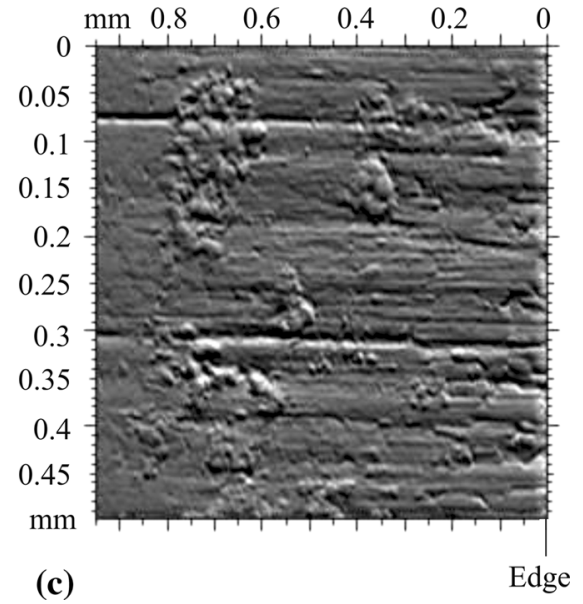

Fig. 12 Punch flank surface of the M3:2 material: (a) after initial cuts, (b) after 500,000 cuts, (c) after 800,000 cuts (4\% of blanking clearance, surface scan)

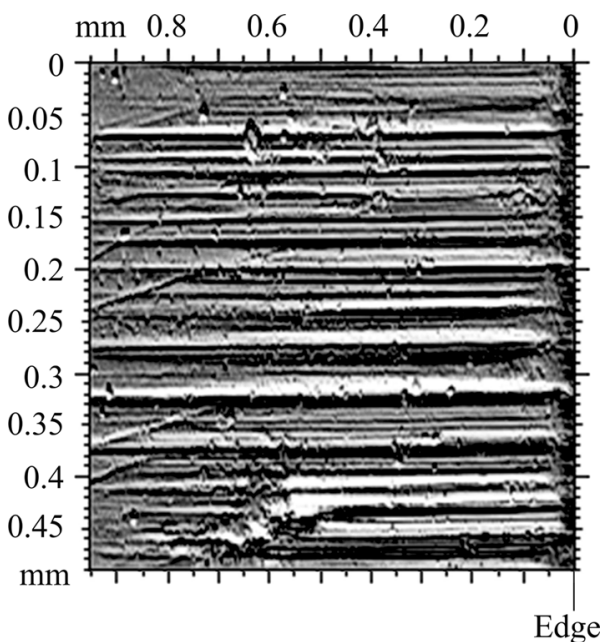

Fig. 13 Flank surface of the M2 punch material after 500,000 cuts ( $4 \%$ of blanking clearance, surface scan)

their size value largely depend on the blanking clearance (Fig. 21). The intensity of that changes depends on the tool wear. The plastic deformations zones are: rounding zone $\left(r_{o}\right)$ and cut zone $\left(z_{s}\right)$-Fig. 21. During the blanking process with wear-out tool, the rounding and the cracking zones are increasing, and the intersection zone is decreasing.

The blanking process with M2 steel punch was stopped after 500,00 cuts because the burr height value was $36-38 \mu \mathrm{m}$. The blanked sheets and tools are contacted dynamically. It results in material spalling (Fig. 22), which results of local increasing of the burr height. Thus, the comparison of punch material and coating layer was made up to 500,000 cuts (Fig. 23). The biggest differences of the burr height for 800,000 cuts were obtained for $0 \%$ of blanking clearance. For the M2 steel material, applying of the TiN coating layer resulted in the biggest increasing effect of the tool durability. Slightly small tool durability increasing effect was obtained for M3:2 steel material at 500,000 cuts. During the blanking process with $0 \%$ of blanking clearance, the punch edges wear is more intensive. The M2 steel punches with TiN coating layer had the smallest wear resistant from all punches with coatings (Fig. 24 and 25).
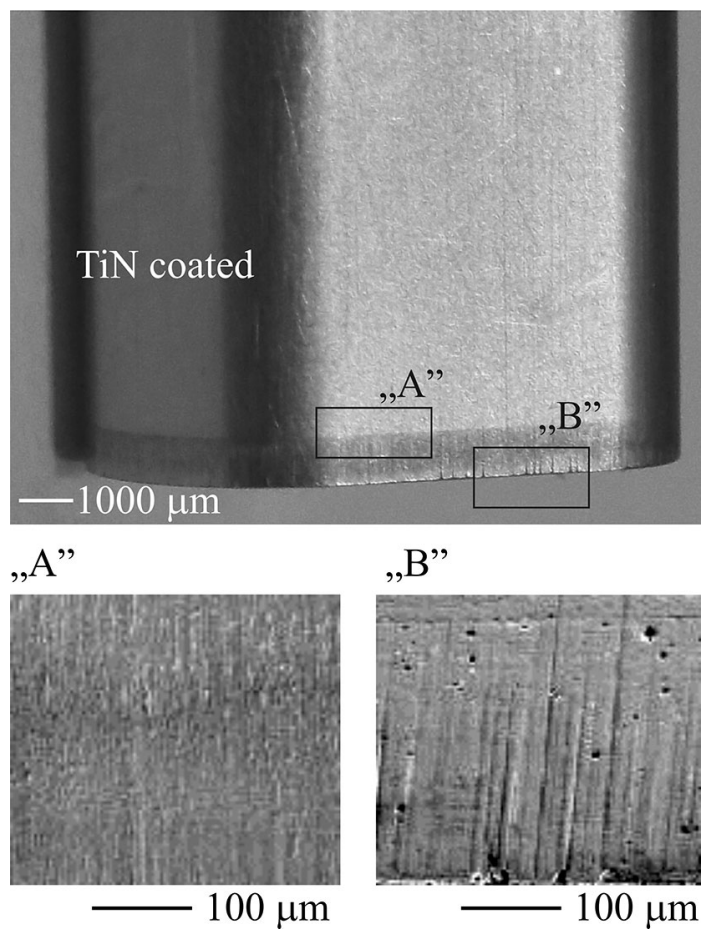

Fig. 14 Punch flank surface after a several thousand cuts (punch with TiN coating, $L_{z}=0 \%$ )

To analyze the influence of blanking clearance on the increase intensity of burr height, the shearability indicator $\left(W_{i}\right)$ was defined as:

$W_{i}=\frac{n}{h_{\mathrm{b}}}$

$n$-number of sheared blanks, $h_{b}$-average burr height measured on selected edge of sheared blank.

During the blanking process, different blanking clearance $\left(L_{z}=0,4,8 \%\right)$ and different punches material with TiN coating layers were used. Differentiation of the blanking clearances and punch materials made it possible to analyze the impact of the blanking clearance on the shearability rate 


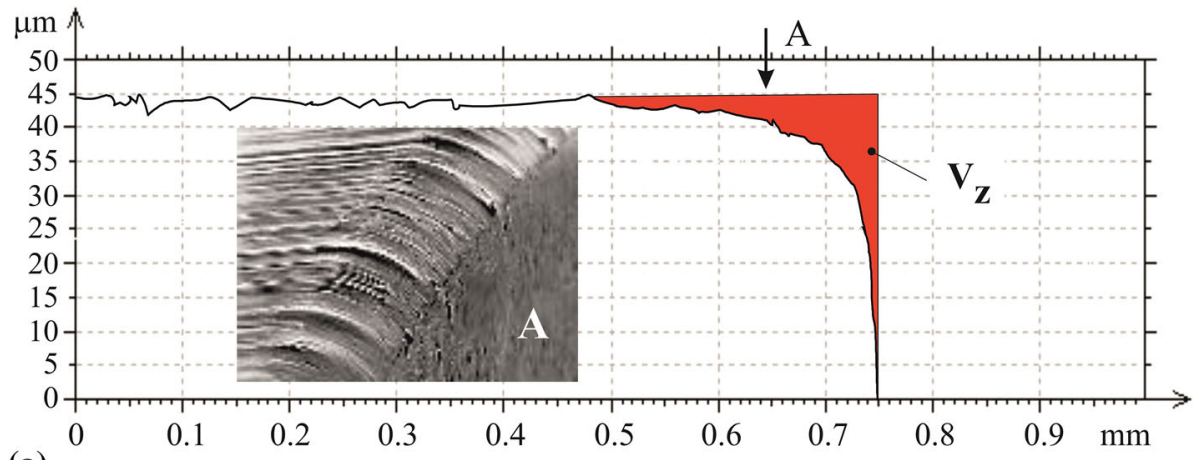

(a)

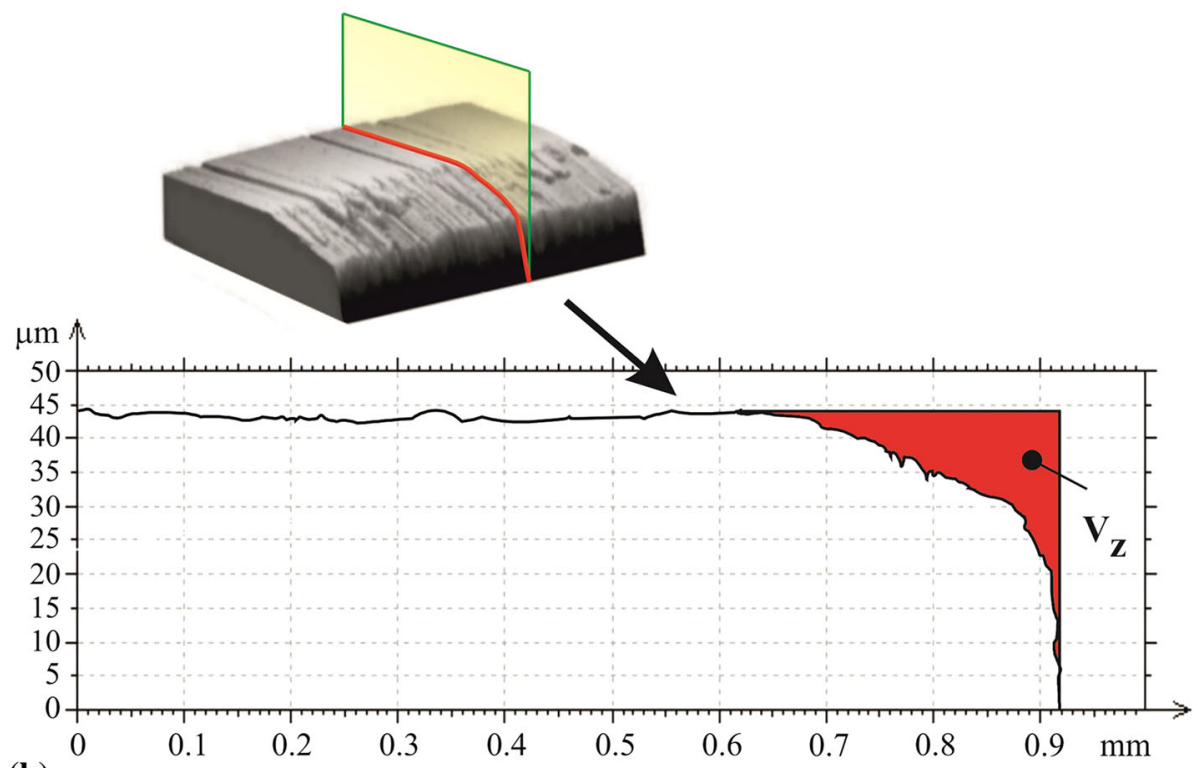

(b)

Fig. 15 Punch cutting edge changes after 800,000 cuts (tool with TiN coating); punch profile for blanking clearance: (a) $L_{z}=8 \%$; (b) $L_{z}=0 \%$

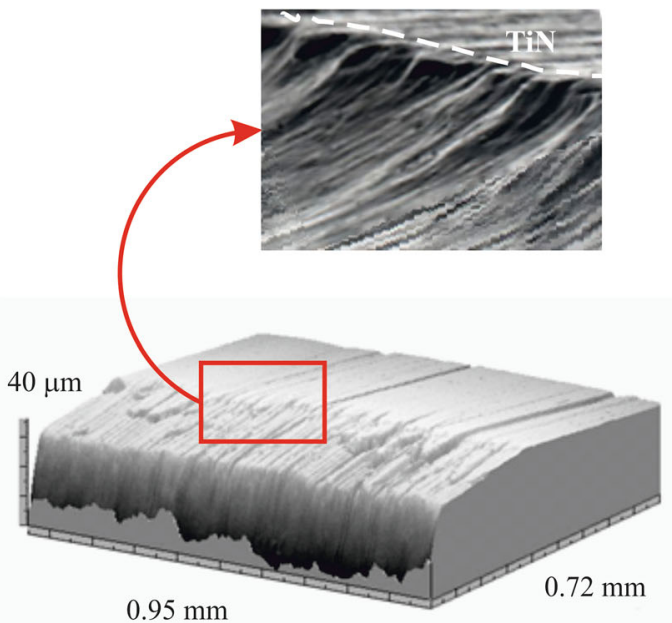

(a)

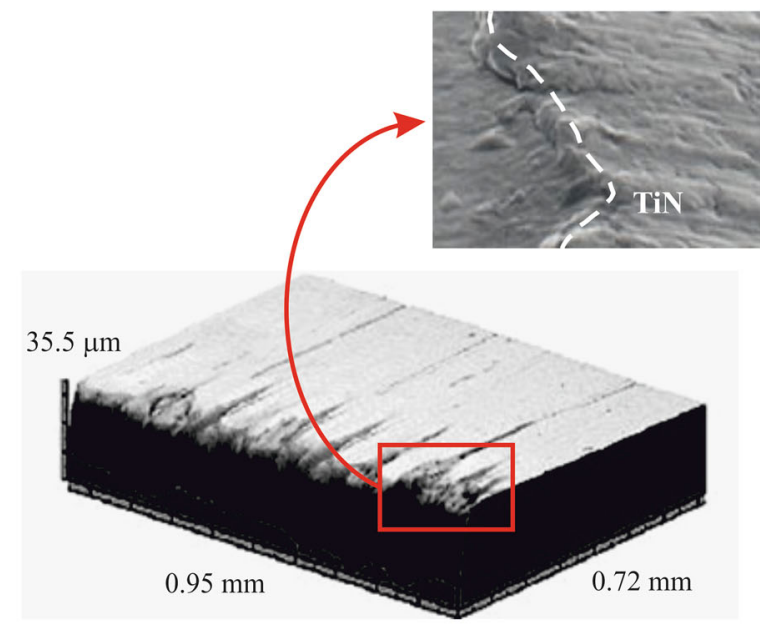

(b)

Fig. 16 Flank surface of the M2+TiN punch material after 800,000 cuts with blanking clearance: (a) $0 \%$, (b) $8 \%$

as a function of the cuts number. In the analysis of the shearability rate, the blanking clearance impact on the shearability rate curve rise was obtained (Fig. 26). For the blanking process with the $8 \%$ of blanking clearance, the highest shearability was obtained (low values of the average burr height on the sheared blanks). Reduction in the blanking 

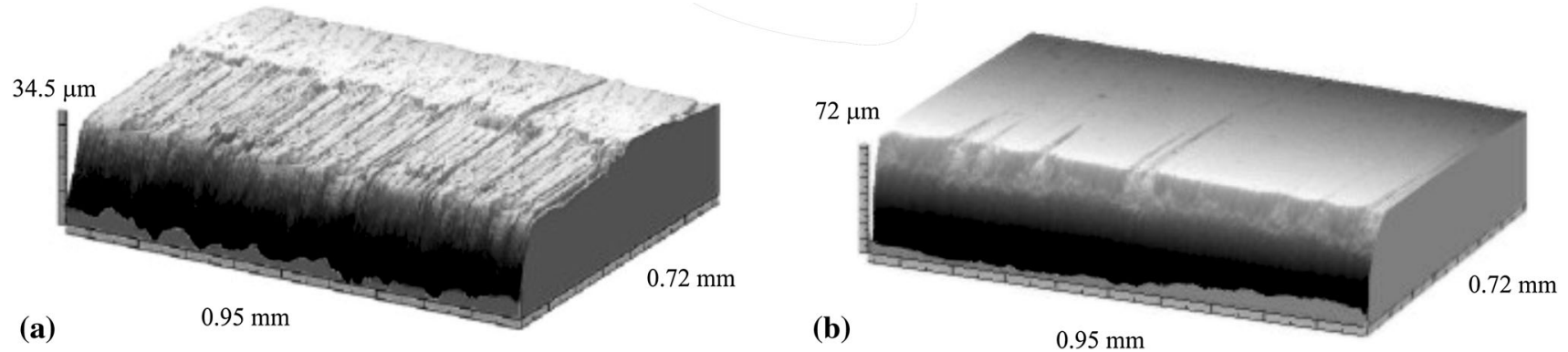

Fig. 17 Flank surface of the M3:2+TiN punch material after 800,000 cuts with blanking clearance: (a) $0 \%$, (b) $8 \%$

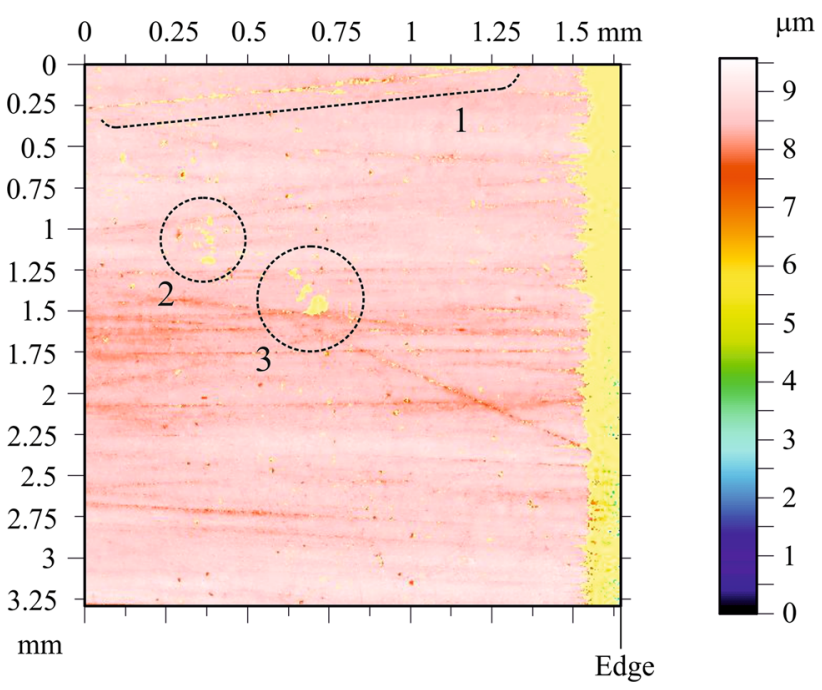

Fig. 18 Punch flank surface fragment after 800,000 cuts with $8 \%$ of blanking clearance (punch material: M3:2+TiN)

(a)
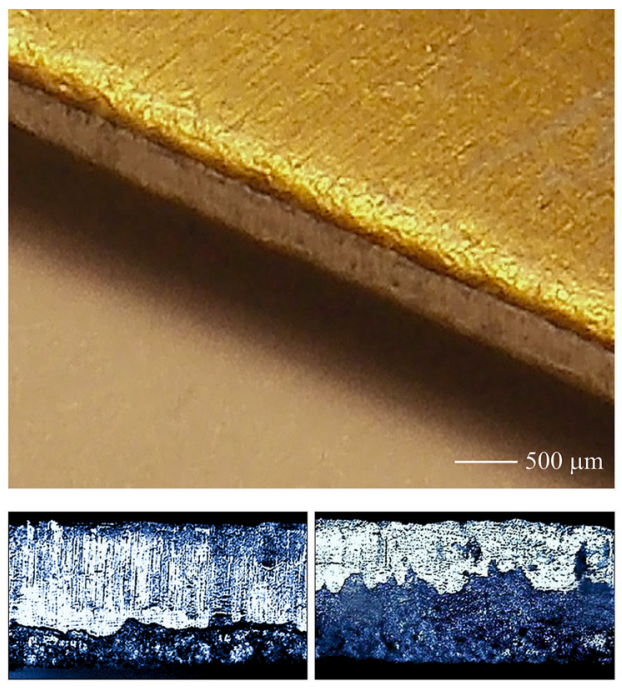

(b)

$-100 \mu \mathrm{m}$ (c)

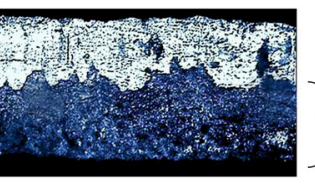

Fracture

Fig. 19 Sheet material surface: (a) C6 coating surface quality, and the intersection for the $8 \%$ of blanking clearance-(b) after initial cuts, (c) after 800,000 cuts

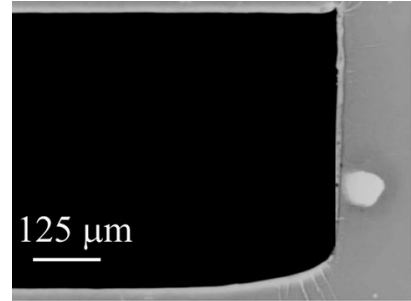

(a)

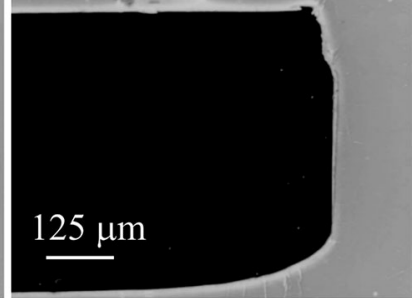

(b)
Fig. 20 Intersection surface boundary for the initial cuts for blanking clearance: (a) $0 \%$ and (b) $8 \%$ (M3:2+TiN punch materials)

clearance from 4 to $0 \%$ for the M3:2+TiN punch materials affected minimally the shearability rate curve. After achievement of 600,000 cuts, the shearability rate curve slope significantly decreased. In the case of M2+TiN punch materials for the blanking clearance $L_{z}=0 \%$, the value of the shearability rate starts decreasing after 600,000 cuts, for $L_{z}=4 \%$ after 650,000 cuts and for $L_{z}=8 \%$ after 700,000 cuts. This was due to achieving the fatigue strength limit of the tool material, which caused increasing of the tool edge wear and increasing of the burr height. The most preferred shearability for the three values of blanking clearance was obtained for the M3:2+TiN punches.

\subsection{Plastic Deformation Zone}

Despite the sheet deformation during the blanking process, the C6 coating type was not pull. Both straight (Fig. 27a) and curved (Fig. 27b) intersection line the coating has a coherent structure with the sheets material.

The cutting edge wear has a big impact on the size of the hardening zone close to the intersection line. The initial changes of the blanked material structure are results of the selected blanking clearance. The sheet material has an appropriate grain primary structure (Fig. 3). The blanking process caused the changes of the grain size and its position in zone close to intersection surface.

During the cuts number, increasing the tools surfaces and cutting edges are wear-out. An example of microstructure changes, close to the intersection surface as a result of blanking with sharp (Fig. 28a) and wear-out punch (Fig. 28b), is presented. Hence, the punch-die clearance is increasing, and the shear stress directions are changing in accordance with the theoretical intersection surface (Ref 7). The hardening area increases as a result of deformation close to the cutting surface. 


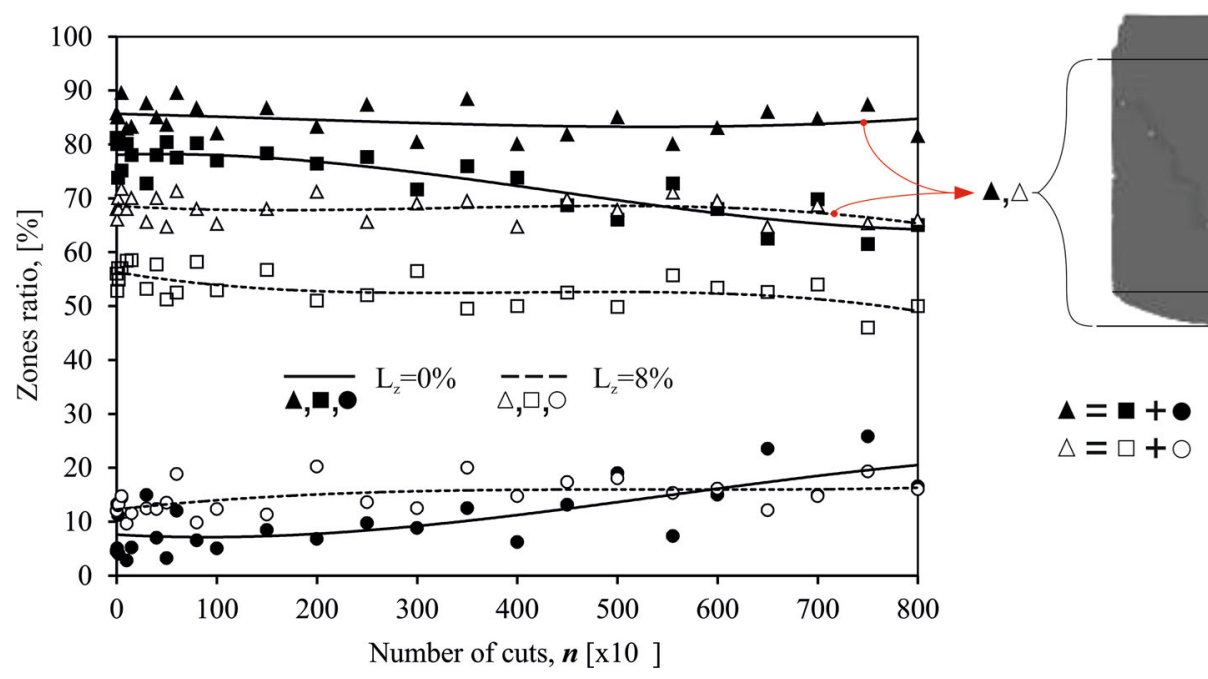

Fig. 21 Sheet intersection surface for the $L_{z}=0$ and $8 \%$ of blanking clearance (M3:2+TiN punch material)

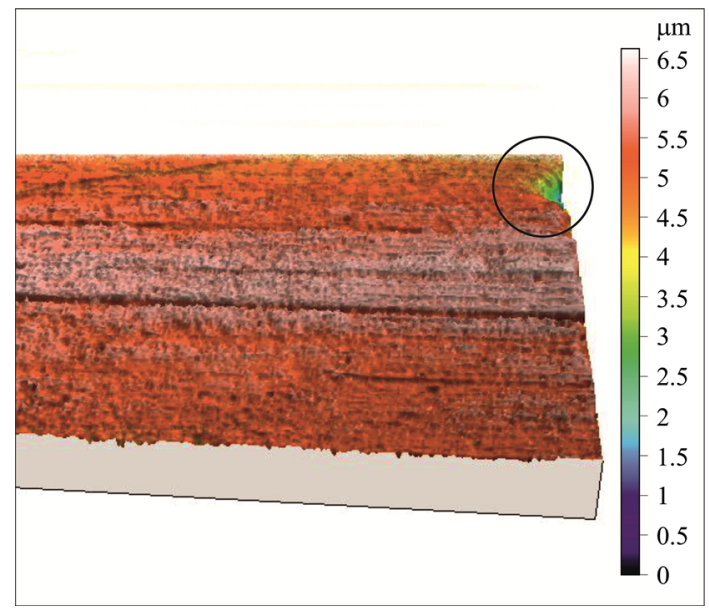

Fig. 22 Tool edge spalling after initial cuts

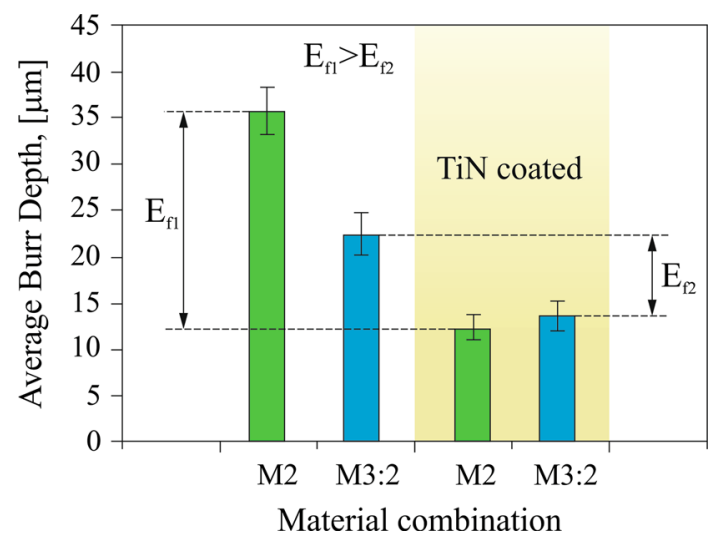

Fig. 23 Average burr height achieved after 500,000 sheared blanks for various punch material $\left(L_{z}=4 \%\right)$

The tools geometry changes influence on the value and size of microhardness changes of the sheet material in vicinity of the cutting line. The hardened layer thickness is related to plastic

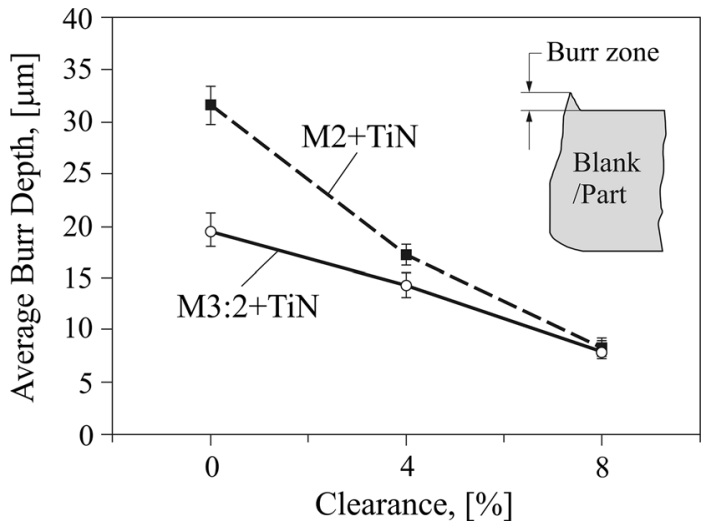

Fig. 24 Average burr height after 800,000 sheared blanks for various values of the blanking clearance

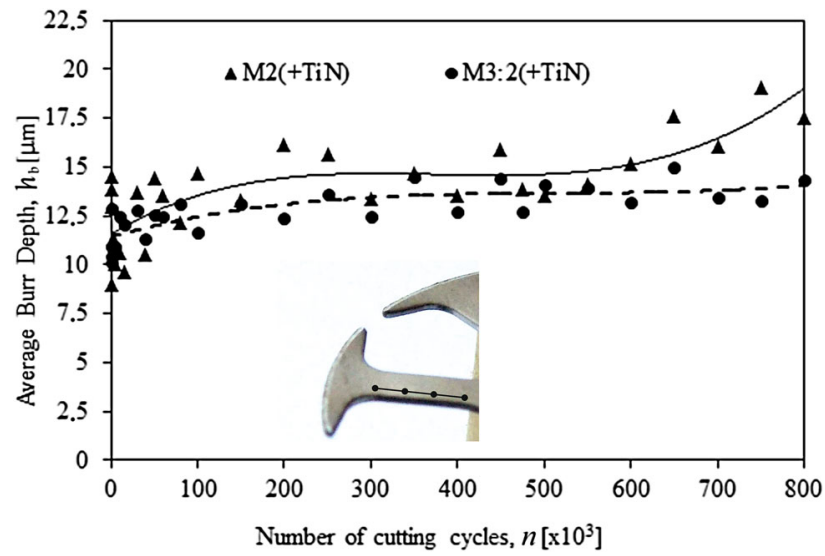

Fig. 25 Comparison of the average burr height course on the product for punches made of the M2+TiN, and M3:2+TiN with $L_{z}=4 \%$

deformation phase. As the value of plastic deformation is increasing, the thickness and hardness increase in strengthened layer are greater. 

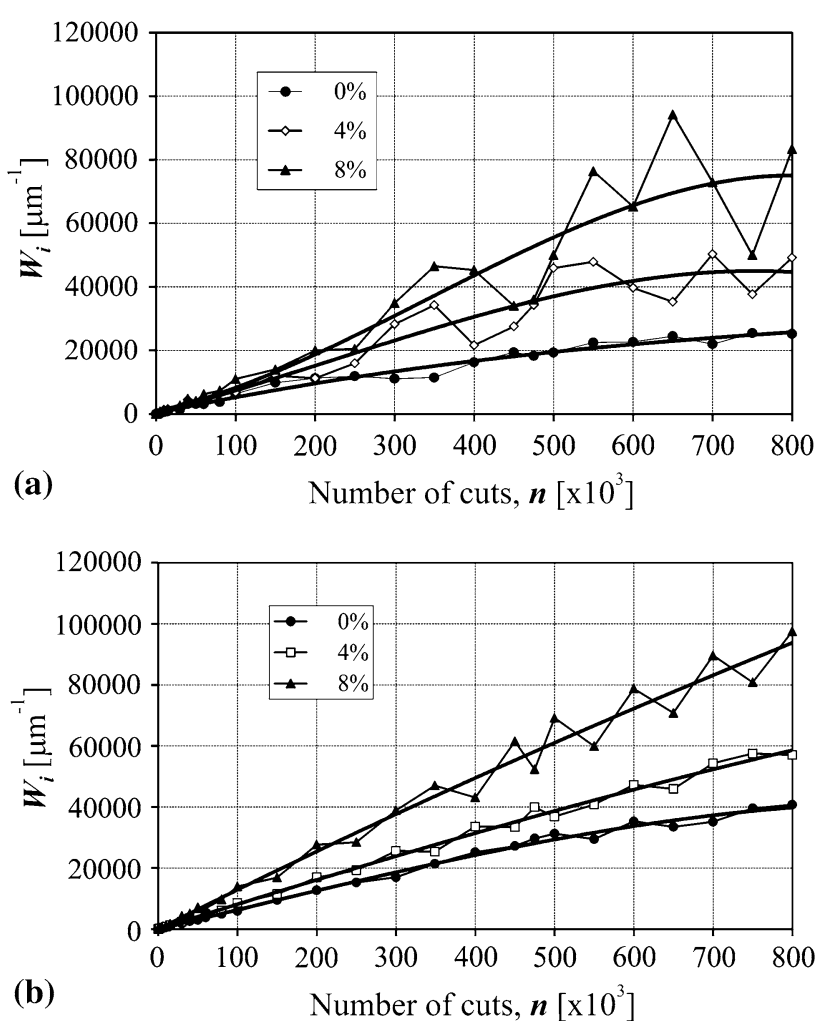

Fig. 26 Punchability rate dependence on blanking clearance for punches material: (a) M2+TiN, (b) M3:2+TiN

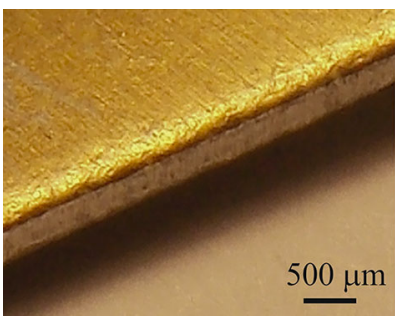

(a)

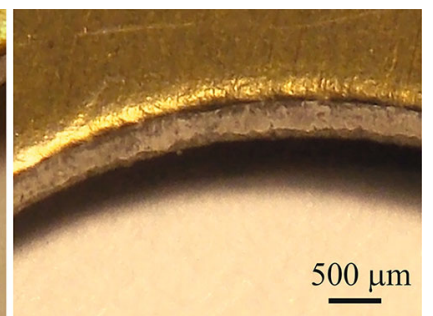

(b)
Fig. 27 Silicon steel sheet coating layer close to the intersection surface

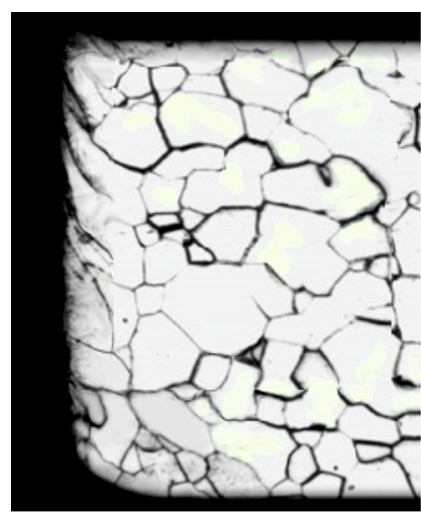

(a)
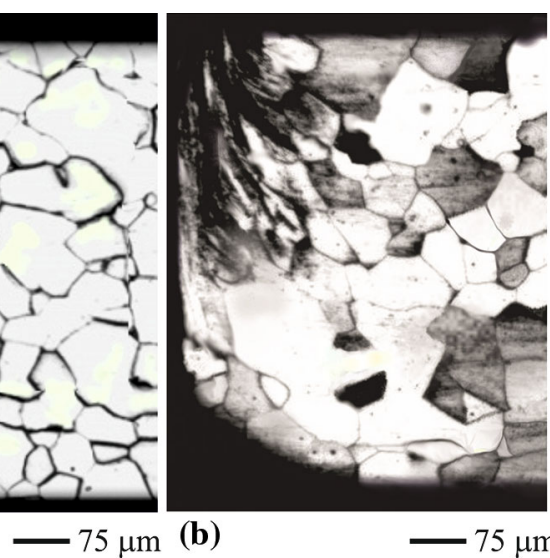

(b)

$-75 \mu \mathrm{m}$

Fig. 28 Sheet material structure close to the intersection surface $\left(L_{z}=0 \%\right)$ : (a) for initial cuts, (b) after 800,000 cuts
Each of the changes of the grain structure size by work hardening or annealing is affecting on the magnetic properties of sheet material (Ref 29, 30). Therefore, the appropriate blanking clearance and punch material choose, for keeping stable and predictable blanked material deformations, is an extremely important issue. The hardness changes measurement after the blanking process allows to define the zone of the microstructure changes and thereby to define the magnetic properties changes of blanked parts (Ref 31$)$.

The maximum increase of M530-50A silicon steel sheet material hardness changes was observed close to the cutting line (Fig. 29), in the vicinity of the crack initiation after the end of plastic cutting phase. The sheets microhardness for all samples was about $250 \mathrm{HV} 0.1$. The difference was in the size of the maximum hardness zone. The hardness of the most strained material was 1.72 times greater than the average hardness of undeformed sheets (145 HV0.1). The material strengthening is so high that the plastic cutting phase is end, and appearing microcracks begin the fracture phase. The microhardness distribution and size of the hardness changes zone were depended on the punch wear. During the cutting edge wear-out process, the strain state was changing, which caused the changes of the material strengthening process. In addition, the microhardness distribution, close to the intersection surface, after the initial cuts was different for different values of blanking clearance ( 0 and $8 \%$ ). For clearance close to $0 \%$, the zone of the deformation changes is relatively small (Fig. 29-1). It increases with the tool wear (Fig. 29-2 and 3). The tool wear during the blanking process significantly increases the plastic strain zone and deteriorates the magnetic properties of the sheared blank. In blanking process with $8 \%$ of blanking clearance, the zone of plastic deformation (Fig. 29-4, $5,6)$ is greater than in case with $0 \%$ of blanking clearance.

\section{Summary}

The quality of the sheared blanks, which are used for rotor and stator elements in the electrical motors, depends on several blanking process parameters. For the generator sheets blanking process, application of the punches with additional TiN coating layer reduces the cutting edge wear intensity and expands the period of the tool normal use. The abrasion was greatest for the TiN coating layer applied on the M3:2 punch material. For the $\mathrm{M} 2+\mathrm{TiN}$ punch materials, the mixed wear process was obtained. Despite the maintenance of constant condition in blanking process, the zone of the hardened material microstructure was expanding.

The experimental research has shown that there is a blanking clearance which ensures the possibilities of having the constant burr height value for relatively large number of cuts. For the large value of the blanking clearance, the burr height can be reduced by the material structure which will be more deformed.

The size of the clearance between the punch and die cutting edges has significant influence on the tool cutting edge wear and the sheared blanks quality. In the case of $0 \%$ of blanking clearance, the tool cutting edge wear is more intensively, the burr height is higher, and the plastic deformation zone is smaller. The grains are less deformed than for $8 \%$ of blanking clearance. Blanking with bigger size of the punch-die clearance results in decreasing the cutting tool wear intensity, but the 

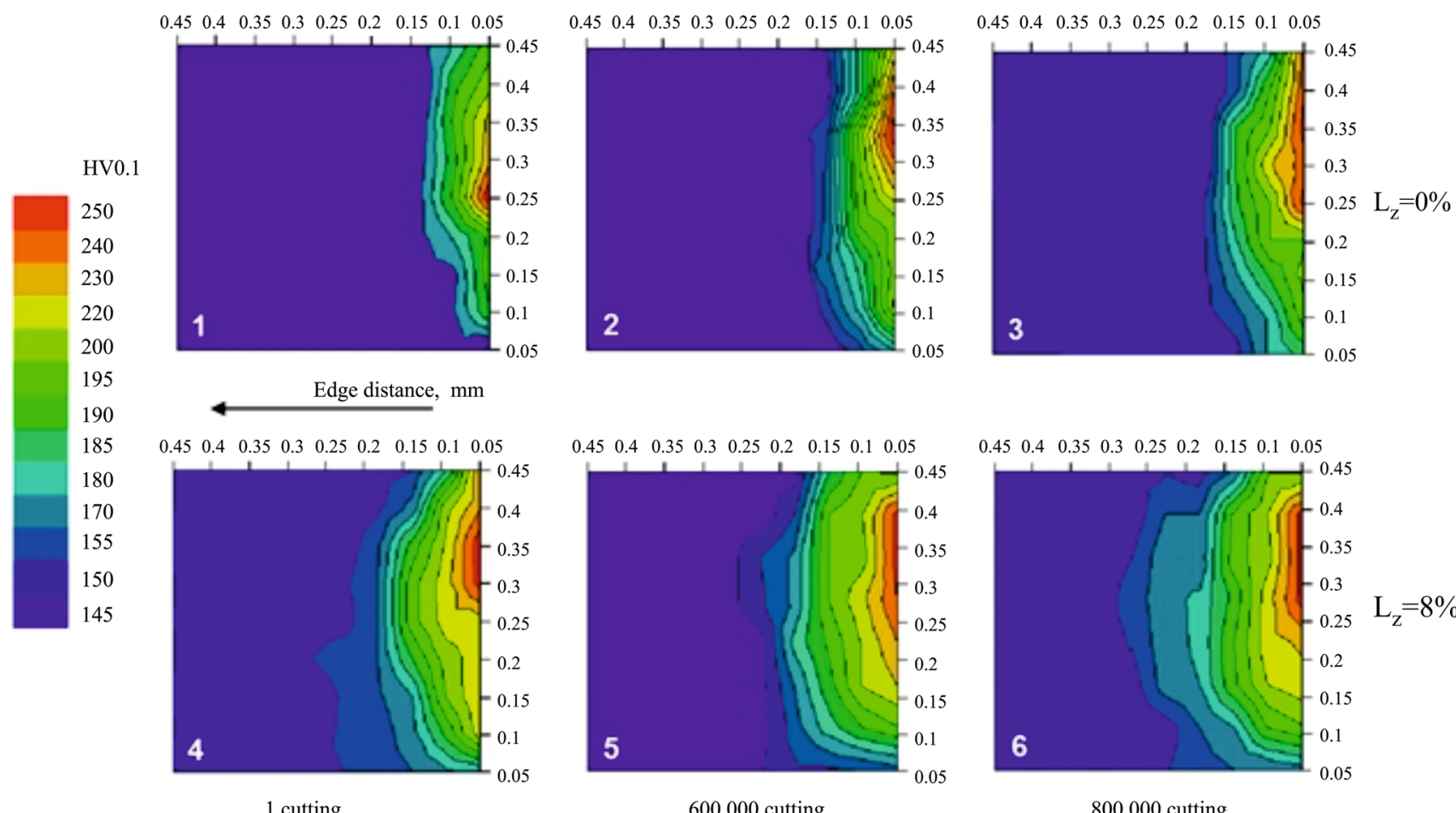

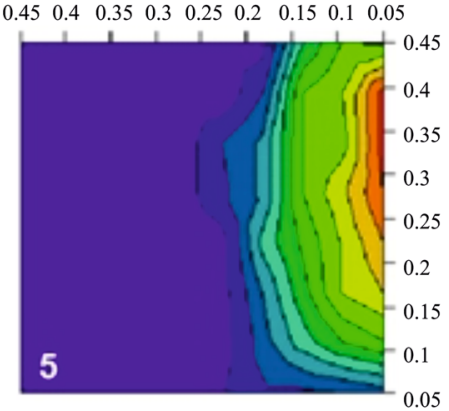

600000 cutting

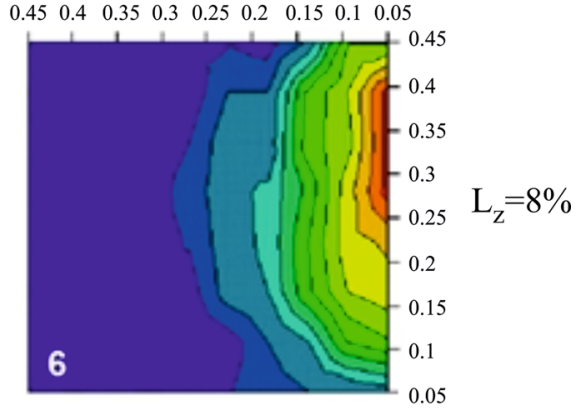

800000 cutting

Fig. 29 Microhardness distribution on the sheared blank cross section in vicinity of separation surface for blanking process with $L_{z}=0$ and $8 \%$ of blanking clearance after specified number of cuts (M3:2+TiN punch material)

sheared blanks intersection surface quality is worst and the zone of plastic deformation is extending.

\section{Open Access}

This article is distributed under the terms of the Creative Commons Attribution 4.0 International License (http://creativecom mons.org/licenses/by/4.0/), which permits unrestricted use, distribution, and reproduction in any medium, provided you give appropriate credit to the original author(s) and the source, provide a link to the Creative Commons license, and indicate if changes were made.

\section{References}

1. J. Mucha, The Analysis of Selected Material Suitability for Tools Used for Blanking the Commutator Motor Elements. In: Proceedings 9th International Scientific Conference, Applied Mechanics, Ostrawa, VŠB-Technical University of Ostrawa, Czech Republic, 2007, p $171-172$

2. W. Wilczyński, Influence of Magnetic Circuit Production for Their Magnetic Properties, J. Mater. Sci., 2003, 38, p 4905-4910

3. S.V. Ponnaluri, R. Cherukuri, and P.A. Molian, Core Loss Reduction in Grain-Oriented Silicon Steels by Excimer Laser Scribing. Part I: Experimental Work, J. Mater. Process. Technol., 2001, 112, p 199-204

4. H. Naumoskia, B. Riedmüllerb, A. Minkowb, and U. Herr, Investigation of the Influence of Different Cutting Procedures on the Global and Local Magnetic Properties of Non-Oriented Electrical Steel, J. Magn. Magn. Mater., 2015, 15, p 126-133

5. F. Gréban, G. Monteil, and X. Roizard, Influence of the Structure of Blanked Materials upon the Blanking Quality of Copper Alloys, $J$. Mater. Process. Technol., 2007, 186, p 27-32

6. Z. Tekiner, M. Nalbant, and H. Gürün, An Experimental Study for the Effect of Different Clearances on Burr, Smooth-Sheared and Blanking Force on Aluminium Sheet Metal, Mater. Des., 2006, 27, p 1134-1138
7. L.V. Raulea, A.M. Goijaerts, L.E. Govaert, and F.P.T. Baaijens, Size Effects in the Processing of Thin Metal Sheets, J. Mater. Process. Technol., 2001, 115, p 44-48

8. J.J. Hernández, P. Franco, M. Estrems, and F. Faura, Modelling and Experimental Analysis of the Effects of Tool Wear on Form Errors in Stainless Steel Blanking, J. Mater. Process. Technol., 2006, 180, p $143-150$

9. S. Golovashchenko, A Study on Trimming of Aluminum Autobody Sheet and Development of a New Robust Process Eliminating Burrs and Slivers, Int. J. Mech. Sci., 2006, 48, p 1384-1400

10. S.F. Golovashchenko, Analysis of Trimming of Aluminum Closure Panels, J. Mater. Eng. Perform., 2007, 16, p 213-219

11. S.F. Golovashchenko, Quality of Trimming and Its Effect on Stretch Flanging of Automotive Panels, J. Mater. Eng. Perform., 2008, 17, p 316-325

12. W. Klingenberg and T.W. de Boer, Condition-Based Maintenance in Punching/Blanking of Sheet Metal, Int. J. Mach. Tools Manuf., 2008, 48, p 589-598

13. P. Chumrum, N. Koga, and V. Premanond, Experimental Investigation of Energy and Punch Wear in Piercing of Advanced High-Strength Steel Sheet, Int. J. Adv. Manuf. Technol., 2015, 5, p 1035-1042

14. B.S. Levy and C.J. Van Tyne, Review of the Shearing Process for Sheet Steels and Its Effect on Sheared-Edge Stretching, J. Mater. Eng. Perform., 2012, 21, p 1205-1213

15. H.E. Theis, Handbook of Metalforming Processes, Taylor \& Francis, London, 2015, ISBN 9780824793173

16. O.O. Araujo Filho, M.D.M. das Neves, J.F. Liberati, L.C.E. da Silva, L. Salgado, and F. Ambrozio Filho, Sintering of AISI, M3:2 High Speed Steel-Part II, Mater. Sci. Forum, 2006, 530-531, p 358-363

17. D-Ch Hu, M.-H. Chen, J.-D. Ouyang, and L.-M. Yin, Finite Element Analysis of the Thermal Effect in High-Speed Blanking of Thick Sheet Metal, Int. J. Adv. Manuf. Technol., 2015, 80, p 1481-1487

18. W. Guo and H.-Y. Tam, Effects of Extended Punching on Wear of the WC/Co Micropunch and the Punched Microholes, Int. J. Adv. Manuf. Technol., 2012, 9, p 955-960

19. S. Bać, J. Jaworski, and F. Stachowicz, Durability Dependence on Cutting Tool Material in Blanking Process of Generator Sheet Metal. In: Proceedings Conference Technology' 99, Bratislava, SlovakRepublic, 1999, p. 452 
20. L. Hong, G. Bian, S. Hu, L. Wang, and H. Dacosta, Tribological Properties of CrAlN and TiN Coatings Tested in Nano- and Microscale Laboratory Wear Tests, J. Mater. Eng. Perform., 2015, 24, p 2670-2677

21. C.F. Cheung, W.B. Lee, and W.M. Chiu, An Investigation of Tool Wear in the Dam-Bar Cutting of Integrated Circuit Packages, Wear, 2000, 237, p 274-282

22. S.-P. Lo, D.-Y. Chang, and Y.-Y. Lin, Quality Prediction Model of the Sheet Blanking Process for Thin Phosphorous Bronze, J. Mater. Process. Technol., 2007, 194, p 126-133

23. ASTM A976-13. Standard Classification of Insulating Coatings for Electrical Steels by Composition, Relative Insulating Ability and Application. ASTM International, 2013, p. 5

24. H. Makich, L. Carpentier, G. Monteil, X. Roizard, J. Chambert, and P. Picart, Metrology of the Burr Amount-Correlation with Blanking Operation Parameters (Blanked Material-Wear of the Punch), Int. J. Mater. Form., 2008, 1, p 1243-1246

25. J. Mucha, An Experimental Analysis of Effects of Various Material Tool's Wear on Burr During Generator Sheets Blanking, Int. J. Adv. Manuf. Technol., 2010, 5-8, p 495-507
26. A. Mubarak, P. Akhter, E. Hamzah, M. Radzi, M.R.H.J.M. Toff, and I.A. Qazi, Effect of Coating Thickness on the Properties of Tin Coatings Deposited on Tool Steels Using Cathodic Arc PVD Technique, Surf. Rev. Lett., 2008, 4, p 401-410

27. D. Gaworska-Koniarek, J. Bajorek, and W. Wilczyński, Local Magnetisation of a Grain-Oriented Electrical Steel Sheet, Prz. Elektrotech., 2015,4, p 24-27

28. R. Baumann, R. Siebert, P. Herwig, A. Wetzig, and E. Beyer, Laser Remote Cutting and Surface Treatment in Manufacturing Electrical Machines-High Productivity, Flexibility, and Perfect Magnetic Performance, J. Laser Appl., 2015, 27, p 1-6

29. M. Emura, F.J.G. Landgraf, W. Ross, and J.R. Barreta, The Influence of Cutting Technique on the Magnetic Properties of Electrical Steels, $J$. Magn. Magn. Mater, 2003, 254-255, p 358-360

30. I. Petryshynets, F. Kovac, J. Marcin, and I. Škorvanek, Improved Processing Technique for Preparation of Non-oriented Electrical Steels with Low Coercivity, Acta Phys. Pol. A, 2014, 126, p 182-183

31. E.G. Araujo, J. Schneider, K. Verbeken, G. Pasquarella, and Y. Houbaert, Dimensional Effects on Magnetic Properties of Fe-Si Steels due to Laser and Mechanical Cutting, IEEE Trans. Magn., 2010, 46, p 213-216 